\title{
What Motivates and Engages Students in the Education Process-An Examination of Qatari Students' Mindset and Attitudes toward Going to School, Learning, and Future Aspirations
}

\author{
Seungah Lee ${ }^{1}$ \\ ${ }^{1}$ Doha, Qatar \\ Correspondence: Seungah Lee, Doha, Qatar. E-mail: seungah_lee@mail.harvard.edu
}

Received: May 6, 2016

Accepted: May 25, 2016

Online Published: June 26, 2016

doi:10.5539/jel.v5n3p220

URL: http://dx.doi.org/10.5539/jel.v5n3p220

\begin{abstract}
This paper examines student attitudes towards school and learning among students in Qatar's public schools. Drawing upon student surveys administered to 1091 grade 7 and 8 students in 11 independent preparatory schools, the paper observes patterns of attitudes and behavior towards learning, school, and future aspirations. Findings show that student articulation of importance of education, finding learning in the classroom as useful, demonstration of learning behavior in and outside the classroom, and future aspirations to enroll in university are positively associated with attitudes toward going to school. Moreover, findings reveal that gender and nationality gaps exist when it comes to school engagement. Boys and Qatari students appear to have less positive attitudes toward going to school compared to girls and non-Qatari students. Once the Qatari and non-Qatari comparison groups are further disaggregated by gender, findings suggest that Qatari boys least value education. Student survey results further indicate that although overall teaching and classroom environment does not appear to have a significant influence on student attitudes toward going to school, fostering a positive culture and learning environment corresponds positively with higher attitudes toward going to schools for boys. Provided that Qatar's national vision places importance in national human capital development through education and has identified student motivation as a challenge, the paper discusses implications for policy, programs, and practice to improve student engagement and learning.
\end{abstract}

Keywords: attitudes and mindset toward school, public schools, Qatar, school engagement, student motivation

\section{Introduction}

Arab Gulf states (Bahrain, Kuwait, Oman, Qatar, Saudi Arabia, and the UAE) have long recognized the need to diversify its economy by reducing its dependence on hydrocarbons and working towards building a knowledge-based economy. The beginning of the $21^{\text {st }}$ century, in fact, marked a turning point for these countries, where many recognized that major social and economic reforms are needed to avoid future economic decline and address the growing levels of unemployment among young people in the region (Kabbani \& Kothari, 2005; Sochat, 2008). As a result, Arab Gulf states set long-term national visions for growth and development towards a knowledge-based economy and placed human capital development and education at the forefront of their respective national agendas (Al Thani, 2012).

In an effort to improve their respective education systems, Gulf states have largely focused their reform efforts on making investments in "hard" infrastructure, better managing overall performance of school systems, and increasing the number of teachers to promote student achievement (Barber, Mourshed, \& Whelan, 2007). Despite such efforts, student achievement in the Gulf states has continued to be significantly below international averages, as evidenced by results from international assessments such as Programme for International Student Assessment (PISA) and Trends in International Mathematics and Science Study (TIMSS) (Organization for Economic Cooperation and Development [OECD], 2014; Mullis, Martin, \& Foy, 2012). Low student achievement in the Gulf states, compared to that in their international counterparts, is concerning, as continued underachievement will likely impede realization of the Gulf states' respective development goals to build a knowledge-based economy and compete in a global economy. In fact, the recent decline in oil prices and demographics of the Arab Gulf region, with more than $40 \%$ of the region's population being under the age of 15 , 
further contribute to the challenge and need to invest in human capital development and improve education outcomes in the region (De Boer \& Turner, 2007; Shediac, 2010).

Establishment of a knowledge economy requires its citizens to have the right skills and competencies but also the desire and willingness to participate and contribute, thereby necessitating its citizens to take ownership of process and learning required to build a knowledge economy (Stiglitz, 1999). If Arab Gulf states truly do desire to establish knowledge-based economies and successfully absorb their respective growing national workforce to contribute towards development, then it is insufficient for these countries to expand education access or to focus on better performance management of their teachers and schools. Rather, a quality education, which is rooted in the sociocultural context in which learning takes place, is necessary to engage and equip young people effectively with the necessary mindset, attitudes, skills, and knowledge to contribute towards national development. Yet, the Arab Gulf states, in their efforts to improve education outcomes, have neither emphasized nor given much attention to understanding the context of the largest stakeholders of education: the students themselves.

An understanding of student perspectives and engagement with learning and schooling in the Arab Gulf region is particularly important, as these students will be the future leaders and drivers of society. The school, and the education process within it, is where children and youth spend the majority of their time acquiring knowledge and skills and growing in their own values, mindset, and aspiration for future economic and civic participation. Henceforth, these countries' potential to realize their goal of building a knowledge-based economy largely hinges on the assumption that students are engaged and participating actively in school. This is because the schooling system is the primary platform where students gain the necessary competencies to realize their potential and yield both individual and social returns, especially as they relate to national development goals. In this sense, engagement in school is an important outcome in its own right. Engagement itself not only improves performances and validates positive expectations about students' abilities but also serves as an important social signal for the present and future (Furrer \& Skinner, 2003). In other words, unless students are willing and/or motivated to engage in education itself, namely in schooling, it may be difficult to educate and empower the future generation to effectively build and sustain a knowledge economy, an important component of Arab Gulf states' respective development agendas.

Recognizing the importance of the students' role and their engagement in the education process, Qatar placed increasing student motivation as a major goal in its National Development Strategy (Qatar General Secretariat for Development Planning, 2011). Nonetheless, student engagement and motivation continue to remain a challenge in Qatar given high rates of absenteeism, little time spent on homework, and low percentage of students who express that they feel happy in school compared to other PISA participating countries and economies (OECD, 2013). Moreover, a Qatar University study revealed that $36 \%$ of the students in the independent (public) schools, and $21 \%$ in private schools exhibit chronic motivation problems (SESRI, 2013). The same study also found that more students in private schools aspire to a career in the knowledge economy than students in the independent schools at all levels of education and that the percentage of Qatari students planning to obtain a bachelor's degree is lower than non-Qatari students (SESRI, 2013). The fact that more students in the independent school system exhibit signs of motivational challenges and do not aspire for careers in the knowledge economy compared to those in other schools presents a concern for Qatar, as the independent schools comprise the public education system intended to serve the majority of its local national population. Examining patterns of Qatar's independent school students' attitudes toward school, learning, and future aspirations, therefore, can provide further insight into students' mindsets and values that influence their current engagement with the learning process, which is likely to have significant bearing on future economic and civic engagement.

Although student motivation has been highlighted as an education challenge in Qatar and likewise in other Arab Gulf countries (Ashcraft, 2007; Engin \& McKeown, 2012), very few studies have examined student motivation, attitudes towards, and engagement with schooling in the Arab Gulf context. Growing in understanding of student desires and attitudes to engage in the education process can provide significant insights to future success of the education system in equipping children and youth with the skills and motivation to contribute to society. This paper therefore primarily seeks to examine patterns underlying student attitudes toward going to school in relation to their mindset and behavior toward towards learning, school, and future aspirations using Teach For Qatar's student survey dataset.

The scope of this paper is limited to students in Qatar's independent schools. However, insights from the paper are significant and timely for Qatar, given its continued reform efforts and growing attention to the independent school 
system. Findings from this paper can help shape policies and teaching practice, as the paper identifies potential intrinsic motivators and other factors that educators can leverage to increase student school engagement. In fact, provided that the Ministry of Education's work in Qatar with teachers has revolved around training teachers on developing new strategies that will promote student learning (Zellman et al., 2009), findings will provide insight into potential strategies that can be incorporated and practiced actively in the classroom to engage students further in school. Moreover, since public education systems in the Arab Gulf countries have evolved along similar paths and also face similar issues of motivation, engagement, and underachievement, insights and implications from this paper are also relevant for the wider Arab Gulf context, as they can be transferred to other Gulf countries (Barber et al., 2007). Additionally, insights are valuable in other international contexts as well, as other contexts can learn from Qatar's experience and consider the relationship between attitudes toward school, learning, and future aspirations in thinking about how to better engage students in school and the learning process.

\section{Review of Literature}

The link between engagement and learning has been a longstanding, widely accepted hypothesis, and lack of students' engagement with school, in addition to lack of enjoyment of learning, has been considered as factors for failures in education and for young people failing to achieve their potential (Shernoff et al., 2003; Goetz, Frenzel, \& Pekrum, 2006). Underlying this link is the assumption that learning is contingent on individual willingness to be present and partake in the education process in the first place, which is largely dependent upon participants' attitudes towards the process and/or the platform for learning itself (Lumby, 2011). Furthermore, in examining engagement, research suggests that three attitudinal components of school engagement exist and that they are interrelated with each other: the cognitive, affective, and behavioral (Fredricks, Blumenfeld, \& Paris, 2004; Maio \& Haddock, 2009). The cognitive component is what an individual thinks or believes about school, which includes students' commitment to school and ability to plan and develop strategies for learning. The affective, or emotional, is the feelings or emotions associated with school, which includes students' sense of belonging and attachment to school. The behavioral is the tendency to respond in a certain way to school, which includes behavior such as completing homework and asking and answering questions in class (Mensah, Okeyre, \& Kuaranchine, 2013). An individual's attitude toward school can henceforth be deduced from the learner's behaviors, feelings and expression toward the school and activities within the school, whether positive or negative (Candeias, Rebelo, \& Oliviera, 2013; Bernstein et al., 2006).

With regards to student motivation, research views students as decision makers who weigh and consider the causal attributions, value, and purpose of pursuing education goals (Appleton, Christenson, \& Furlong, 2008). Therefore, individual commitment to academic goals, in addition to the student's psychological connection to school, plays an important role in student motivation and participatory behaviors, as they influence the time students invest toward school and the education process as a whole (Archambault et al., 2009; Appleton et al., 2008). In fact, it is these two factors, individual commitment (i.e., motivation) and psychological connection (i.e., attitudes), that influence students' academic and social experience in school, which in unfavorable conditions, can eventually play a role in the student's decision to disengage and leave the system altogether (Archambault et al., 2009). Understanding patterns of student attitudes and motivation, then, can provide important explanatory insights into the motivational and attitudinal factors and aspects that influence student behavior, approach, and choice regarding student engagement with school.

Additionally, studies have demonstrated that student engagement with school, particularly as they relate to positive attitudes and commitment to learning, corresponds positively with student outcomes (Candeias, Rebolo, \& Oliviera, 2013; Patrick, Ryan, \& Kaplan, 2007; Skinner et al., 2008; Tyler \& Boelter 2008). In the short term, student engagement with learning was found to be a positive predictor for student academic achievement in form of test scores and grades in the short term (Skinner et al., 2008). In the long term, student engagement with school were found to be predictors for patterns of attendance, retention, graduation, and resilience in addition to less likelihood of being engaged in risky behavior (Jimerson, Campos, \& Greif, 2003; Sinclair et al., 2003). Research therefore indicates that student engagement with learning could be a predictor of student academic and non-academic outcomes, where student engagement corresponds positively with student learning and life outcomes. Furthermore, studies have found a steady decline in student engagement with schooling from kindergarten to high school, particularly in areas of interest, intrinsic motivation, and enthusiasm, with the greatest drop occurring during the transition from middle to high school (Wigfield \& Eccles, 2002). The middle school age group, then, provides an interesting and important group to observe as examination of their mindset, affective, and behavior attitudes toward school and learning can provide more in depth explanation to patterns of engagement among students prior to entering high school. 
In further examining the relationship between attitudes and academic achievement, it appears that student attitudes toward school and learning vary across gender and race. Linnehan (2001) found evidence that variables such as beliefs, general attitudes toward school, and attitudes toward specific academic subjects vary across gender and racial lines. Another study found that girls, on average, have more positive attitudes towards school compared to boys and that this was further evidenced in their behavioral patterns such as cases of misconduct in class, absenteeism, and expectations for future education and life outcomes (Van Houtte, 2004).

Provided that literature suggests potential gender and racial differences in attitudes toward school, it is worth considering these characteristics in Qatar's independent school context, given the academic achievement gap between boys and girls in Qatar and the wider Arab Gulf region (Ridge, 2014; SESRI, 2013). Is there reason to believe that student mindset and attitudes toward learning, school, and future aspirations differ between boys and girls and also between Qataris and non-Qataris? The following analysis explores gender and national differences of students' attitudes toward going to school. Furthermore, in considering students' attitudes toward going to school, the classroom and school learning environment cannot be ignored, as students' educational experiences occur within the school institution that structures curricula and learning activities schools in which the students partake (Johnson, Crosnoe, \& Elder, 2001). Hence, the paper also considers the relationship between the classroom and teaching environment in which the student is in and the student's attitude toward going to school.

Following literature review and considering Qatar's context, the paper posits to test the following hypotheses:

$\mathrm{H}_{1}$. Student ability to articulate importance and/or value of education is positively associated with student attitudes toward going to school

$\mathrm{H}_{2}$. Self-perceived demonstration of positive learning behavior in the classroom is positively associated with student attitudes toward going to school

$\mathrm{H}_{3}$. Student articulation of desire to attend university is positively associated with student attitudes toward going to school

$\mathrm{H}_{4}$. Overall positive classroom and teaching environment is positively associated with student attitudes toward going to school

\section{Data and Methodology}

\subsection{Data}

Analysis draws from Teach For Qatar (TFQ)'s student survey dataset containing responses from 1091 grade 7 and 8 students in 11 Qatar's independent preparatory schools (Note 1), of which 4 are boys' schools and 7 are girls' schools. The dataset contains student responses from 2 different surveys: The Student Mindset Survey, developed internally by Teach For Qatar, and the Student Tripod Survey, developed by Ronald Ferguson as part of Measures of Effective Teaching study (Ferguson, 2012).

\subsection{Procedures}

TFQ administered Student Mindset and Tripod surveys in September/October 2015, the beginning of the academic year. The questionnaires were administered in students' regular classrooms, using a standard protocol. Confidentiality was maintained for all data. Given that questionnaires were administered in the beginning of the year, and that students did not have any interaction with the teachers in previous years, student responses could not have been significantly influenced by the work of the TFQ teachers. It is also assumed that participating students' responses in these classrooms would have been no different from that if administered in non-teaching fellow classrooms.

Provided that the two surveys were administered separately and anonymously during a given window, responses for the two surveys could not be matched to individual students but could be matched to the class in which the student belongs. Therefore, the dataset was generated such that each individual student mindset survey responses were combined with aggregate classroom-level responses on the student tripod survey. Table 1 provides background information about the student sample. 
Table 1. Sample distribution of students (frequency)

\begin{tabular}{lcc}
\hline Subgroup & Frequency & Percentage (\%) \\
\hline Nationality & 578 & 52.98 \\
Qatari & 421 & 38.59 \\
Arab (non-Qatari) & 49 & 4.49 \\
Non-Arab & 43 & 3.94 \\
Chose not to respond & & \\
Gender & 369 & 33.73 \\
Male & 723 & 66.27 \\
Female & 1091 & 100 \\
Total & & \\
\hline
\end{tabular}

\subsection{Methodology}

The principal variable of interest, student attitudes toward going to school, is measured by factor analysis, with generated factor scores based on items that load highly on a single factor and thus constitute a measure on student mindset survey results. Factor analysis identified two question items that were originally designed to measure student attitudes toward learning measured on a 5-point likert scale.

Student value of education is coded dichotomous, taking on a value of 1 for students articulating a reason for why education is important and/or valuable on the student mindset survey and a value of 0 otherwise. By this measure, 847 students, or approximately $77.64 \%$ of all student respondents $(72.28 \%$ boys and $80.36 \%$ girls; $72.66 \%$ Qatari and $84.89 \%$ non-Qatari), are classified as valuing education. Another variable for intrinsic motivation, student expression that learning in the classroom as useful, is measured on a 5-point, subjective scale ranging from the "lowest" to the "highest" level of agreement. A variable for future aspiration, desire to attend university, is measured dichotomous, taking value of 1 if student indicated an aspiration to attend university in the future and 0 if otherwise. Student learning behavior is measured by factor analysis, with generated factor scores based on several items that all load highly on a single factor. All items that loaded highly on this factor asked questions regarding student behavior indicated that students are actively engaging with the learning process both in and outside the classroom.

In addition to the attitudinal and motivational factors, influence of overall classroom and teaching environment, as indicated by Student Tripod Survey results, is considered. Controlling for the classroom and teaching environment is important, as studies have shown that students' perceptions of their respective classroom and school environment have an influence on students' engagement with learning and school (Akey, 2006; Fullarton, 2002; Rudd, Reed, \& Smith, 2008). Student Tripod Survey questions are largely categorized into 7 areas (Ferguson, 2012). Provided that individual student responses on the tripod survey could not be matched to that in the student mindset survey due to confidentiality and anonymity, aggregate classroom results were matched to the individual student mindset survey results based on the class to which the student belongs. Each of the 7 categories (Note 2) takes on a composite percentage value of students responding positively to individual questions within the respective category. Dummy variables capturing gender and nationality are also included to consider for gender and nationality differences.

Our resulting statistical model, to be estimated by multivariable regression analysis, is the following:

$$
\begin{gathered}
\text { GOSCHOOL }=\beta_{0}+\beta_{1} \times M A L E+\beta_{2} \times \text { QATARI }+\beta_{3} \times I M P O R T A N T+\beta_{4} \times U S E F U L+\beta_{5} \times \\
\text { LEARNING_BEHAVIOR }+B_{6} \times U N I V E R S I T Y+B_{7} \times \text { ENVIRONMENT }+\varepsilon
\end{gathered}
$$




\section{Findings and Discussion}

Before proceeding to the full model estimation results, bivariate relationships corresponding to student attitudes are considered. These are shown in Table 2, which reports the average level of student attitudes toward going to school as "high" and "low" on each of the variables related to student mindset and behavior toward learning and future aspirations, classified by gender and nationality. For each orientation, the table shows the relative difference in student attitudes toward going to school between Qatari boys, Qatari girls, non-Qatari boys, and non-Qatari girls.

Turning first to students' value of education, the table shows that among Qatari boys who do not articulate the value and/or importance of education, $19.4 \%$ have positive attitudes toward going to school, compared to $48.9 \%$ of those who articulate the value and/or importance of education, a relative difference of $29.5 \%$. This variable seems to be the greatest influencer for Qatari boys' attitudes toward going to school. Among non-Qatari boys, Qatari girls, and non-Qatari girls, the relative influence of articulation of value and/or importance of education is weaker than that for Qatari boys. Nonetheless, articulation of importance of education appears to correspond to higher attitudes toward going to school as expected, with more than $50 \%$ of Qatari female, non-Qatari male, and non-Qatari female students who articulate the importance or value of education having positive attitudes toward going to school. Furthermore, it appears that non-Qatari girls in general have positive attitudes toward going to school compared to other student groups, with even $50 \%$ of those who do not articulate importance and/or value of education still appearing to have positive attitudes toward going to school.

Table 2. Student attitudes toward going to school among students of low and high mindsets toward learning and future aspirations

\begin{tabular}{|c|c|c|c|c|c|c|c|c|c|c|c|c|}
\hline \multirow{2}{*}{$\begin{array}{l}\text { Student mindset } \\
\text { toward learning and } \\
\text { future aspirations }\end{array}$} & \multicolumn{3}{|c|}{ Qatari Boy } & \multicolumn{3}{|c|}{ Non-Qatari Boy } & \multicolumn{3}{|c|}{ Qatari Girl } & \multicolumn{3}{|c|}{ Non-Qatari Girl } \\
\hline & Low $^{\text {a) }}$ & High & Diff. & Low & High & Diff. & Low & High & Diff. & Low & High & Diff. \\
\hline $\begin{array}{l}\text { Articulate importance } \\
\text { and/or value of } \\
\text { education }\end{array}$ & $19.4 \%$ & 48.9 & 29.5 & 27.3 & 53.5 & 26.2 & 33.3 & 52.9 & 19.6 & 50.0 & 66.9 & 16.9 \\
\hline $\begin{array}{l}\text { Learning in classroom } \\
\text { is useful }\end{array}$ & 22.5 & 49.2 & 26.7 & 28.3 & 60.7 & 32.4 & 35.2 & 58.5 & 23.3 & 36.0 & 79.2 & 43.2 \\
\hline $\begin{array}{l}\text { Learning behavior in } \\
\text { and outside the } \\
\text { classroom }\end{array}$ & 31.3 & 49.4 & 18.1 & 22.0 & 65.4 & 43.4 & 32.6 & 64.1 & 31.5 & 44.3 & 75.6 & 31.3 \\
\hline $\begin{array}{l}\text { Desire to go to } \\
\text { university }\end{array}$ & 17.6 & 44.2 & 26.6 & 22.2 & 51.6 & 29.4 & 23.1 & 50.0 & 26.9 & 56.3 & 64.7 & 8.4 \\
\hline
\end{tabular}

Unlike that regarding articulation of value and/or importance of education, student expressing that learning in the classroom is useful appears to be the most influential factor for non-Qatari girls compared to other student groups. This is evidenced by difference in attitudes toward going to school between students with low and high mindset toward learning in the classroom. Attitudes toward going to school is nearly $43.2 \%$ higher for non-Qatari girls with high mindsets toward learning in the classroom, compared to $23.3 \%$ for Qatari girls, 32.4\% for non-Qatari boys, and $26.7 \%$ for non-Qatari boys. With regards to both student demonstration of learning behavior and desire to attend university, it appears that the influence of these two mindsets are strongest for non-Qatari boys compared to other students, with a relative difference of $43.4 \%$ and $29.4 \%$, respectively.

Moreover, percentages reported in Table 2 suggest that non-Qatari female students, on average, appear to have more positive attitudes toward going to school compared to their counterparts across the student mindset variables, especially that against Qatari boy who seem to have the least positive attitudes toward going to school. In fact, it appears that in areas such as articulation of importance of education and desire to go to university, non-Qatari girls who have "low" student mindsets on average have more positive attitudes toward going to school compared to Qatari boys who have "high" mindsets. This indicates that there appears to be a gender and nationality gap in student mindsets and attitudes toward going to school. Nevertheless, bivariate analysis 
suggests that student mindsets toward learning and future aspirations correspond positively with higher attitudes toward going to school for all students.

This pattern is etched more deeply when the fully specified model for student attitudes toward going to school is analyzed. As per multiple regression model estimates in Table 3, there remain the same underlying relationships as that suggested by bivariate analysis even after controlling for teaching and classroom environment. Articulation of importance of education, display of learning behavior, aspiration to go to university, and finding learning in the classroom to be useful are positively associated with higher attitudes toward going to school. This is not surprising given that wider research, mostly based on experiences in the US and the UK, shows that children's self perceptions, such as self-efficacy, autonomy, and goal orientations are robust predictors of motivation and achievement in school, both concurrently and in later years (Eccles, Wigfield, \& Schiefle, 1998; Furrer \& Skinner, 2003; Stipek, 2002). Hence, model estimates affirm that students' own motivational and attitudinal factors, particularly as they relate to student commitment as reflected in their behavior and valuing of education in addition and goal orientation for the future, serve as important influencers for students' engagement with school.

Table 3. Regression model estimate of student attitudes toward going to school

\begin{tabular}{|c|c|c|c|c|}
\hline \multicolumn{5}{|c|}{ Dependent Variable: Attitudes toward going to school } \\
\hline & Model 1 & Model 2 & Model 3 & Model 4 \\
\hline \multirow[t]{2}{*}{ Male } & $-0.228 * * *$ & $-0.300 * * *$ & $-0.269 * *$ & $-0.353 * *$ \\
\hline & $(0.0841)$ & $(0.114)$ & $(0.118)$ & $(0.146)$ \\
\hline \multirow[t]{2}{*}{ Qatari } & $-0.199 * *$ & $-0.215^{* * *}$ & $-0.222 * *$ & $-0.244 * * *$ \\
\hline & $(0.0783)$ & $(0.0801)$ & $(0.0910)$ & $(0.0935)$ \\
\hline \multirow[t]{2}{*}{ Qatari Male } & & & 0.0738 & 0.0894 \\
\hline & & & $(0.167)$ & $(0.171)$ \\
\hline \multirow[t]{2}{*}{ Articulate importance of education } & $0.374 * * *$ & $0.382 * * *$ & $0.375^{* * *}$ & $0.384 * * *$ \\
\hline & $(0.110)$ & $(0.111)$ & $(0.110)$ & $(0.111)$ \\
\hline \multirow[t]{2}{*}{ Display of learning Behavior } & $0.618 * * *$ & $0.617^{* * *}$ & $0.618 * * *$ & $0.617 * * *$ \\
\hline & $(0.0613)$ & $(0.0622)$ & $(0.0614)$ & $(0.0623)$ \\
\hline \multirow[t]{2}{*}{ Aspiration to attend university } & $0.344 * *$ & $0.323 * *$ & $0.349 * *$ & $0.330^{* *}$ \\
\hline & $(0.162)$ & $(0.162)$ & $(0.163)$ & $(0.163)$ \\
\hline \multirow[t]{2}{*}{ Learning is useful } & $0.257 * * *$ & $0.255^{* * *}$ & $0.255^{* * *}$ & $0.254 * * *$ \\
\hline & $(0.0476)$ & $(0.0480)$ & $(0.0478)$ & $(0.0483)$ \\
\hline \multicolumn{5}{|l|}{ Teaching \& Classroom Environment } \\
\hline \multirow[t]{2}{*}{ Encouraging relationships fostered } & & 0.129 & & 0.169 \\
\hline & & $(0.770)$ & & $(0.777)$ \\
\hline \multirow[t]{2}{*}{ Engaging learning environment created } & & 0.322 & & 0.341 \\
\hline & & $(0.836)$ & & $(0.841)$ \\
\hline \multirow[t]{2}{*}{ Learning is internalized } & & $1.713^{*}$ & & $1.711^{*}$ \\
\hline & & $(0.894)$ & & $(0.894)$ \\
\hline \multirow[t]{2}{*}{ Positive culture and learning environment } & & 0.134 & & 0.127 \\
\hline & & $(0.393)$ & & $(0.394)$ \\
\hline \multirow[t]{2}{*}{ Rigorous expectations held } & & -0.503 & & -0.466 \\
\hline & & $(0.916)$ & & $(0.917)$ \\
\hline \multirow[t]{2}{*}{ Student input valued } & & -0.523 & & -0.566 \\
\hline & & $(1.085)$ & & $(1.090)$ \\
\hline
\end{tabular}




\begin{tabular}{lcccc}
\hline \multicolumn{1}{c}{ Checking for understanding } & & $-1.604^{*}$ & & $-1.638^{* *}$ \\
Constant & & $(0.826)$ & & $(0.831)$ \\
& $-0.405^{*}$ & -0.0627 & -0.394 & -0.0571 \\
Observations & $(0.245)$ & $(0.413)$ & $(0.245)$ & $(0.413)$ \\
R-squared & 927 & 927 & 927 & 927 \\
& 0.289 & 0.294 & 0.289 & 0.294 \\
\hline
\end{tabular}

Robust standard errors in parentheses.

$* * * \mathrm{p}<0.01, * * \mathrm{p}<0.05, * \mathrm{p}<0.1$.

Contrary to the assumptions underlying hypothesis 4 of this paper, model estimates show that overall teaching and classroom environment is weakly associated with student attitudes toward going to school (models 2 and 4). This is surprising provided that wider academic literature suggests a positive relationship between teaching and classroom environment and levels of student engagement and academic achievement (Ferguson, 2012; Kane, Kerr, \& Pianta, 2014; Klem \& Connell, 2004). Nonetheless, it seems that only two variables of overall classroom and teaching environment, "teacher ensures that learning is fully internalized" and "teacher checks for understanding", are statistically significant. What is surprising is that the variable "checking for understanding" is negatively associated with student attitudes toward going to school, as it implies that students in classrooms where teacher checks for understanding are less likely to have positive attitudes toward going to school. Nevertheless, the variable "learning is fully internalized", which is correlated with the "checking for understanding" variable ( $\mathrm{r}=$ 0.8615), is positively associated with student attitudes toward going to school. Henceforth, it is difficult to conclude from model estimates whether students being in an environment where the teacher ensures that learning is fully internalized and checks for understanding positively or negatively influences individual students' attitudes toward going to school. Moreover, in interpreting model estimates of variables for the overall classroom and teaching environment, it is important to note that the estimations and corresponding analysis may be limited by the fact that the classroom-level aggregate responses to the question items were included due to limitation of the data. In other words, it is important to recognize that the variables of classroom and teaching environment may have been more significant had individual student responses from the Student Tripod Surveys could be matched to responses in the Student Mindset Surveys. This would have allowed for analysis of direct relationship between individual student perception of the classroom and teaching environment and attitude toward going to school. Despite the limitations, considering the influence of overall classroom and teaching environment that students perceive at the aggregate classroom level is still valuable, as this likely serves as an indicator for overall classroom culture and environment that affect students' engagement with learning in the classroom and school.

Furthermore, model estimates reveal gender and nationality gaps in student engagement with school, where being male or Qatari is negatively associated with more positive attitudes toward going to school. The finding that boys, on average, tend to have less positive attitudes toward going to school compared to girls is consistent with other studies that have found that boys were less engaged in school across secondary years compared to girls, suggesting that this gender gap is not unique to Qatar's context (Fullarton, 2002; Yazzie-Mintz, 2007). In addition, the gender gap in student attitudes toward going to school is further consistent with wider literature on the underachievement of boys in Qatar's public schools with regards to academic achievement, school drop out, repetition, and enrolment in higher education (Menne, 2008; Mullis et al., 2012).

With regards to the gap between Qatari and non-Qatari students in school engagement, a potential explanation for this phenomenon may be provided by the rentier context of Qatar. Political theory postulates that in rentier contexts, such as that in Qatar and the wider Arab Gulf, majority of citizens display low societal capacities, which then translate into low productivity and high expectations from state resources (Hertog, 2010). Although Qatari students are not yet contributing members of society, the future expectations fostered among Qatari students based on the existing societal culture, created by the rentier context, may have influenced these students' attitudes toward and engagement with school and learning from an early age. Students may expect that the state will provide regardless of their individual economic contribution or productivity when they leave school based on their observations with the older generation who display "low societal capacities". This, in turn, could lead Qatari students to believe that their future life outcomes are not highly contingent upon engagement with school and learning process, which would likely influence students' motivation, attitudes, and engagement with school 
negatively, compared to their non-Qatari counterparts whose schooling outcomes likely have a greater bearing on future life outcomes.

Nevertheless, the interaction variable, Qatari Male, is statistically insignificant, suggesting that there does not appear to be a significant difference between Qatari males and its comparison groups. Nonetheless, bivariate analysis indicated that Qatari males seem to have lowest self-perceived mindsets and attitudes toward going to school, learning, and future aspirations. Bivariate analysis further evinced differences in the extent to which variables of student mindsets influence student attitudes toward going to school for Qatari boys, non-Qatari boys, Qatari girls, and non-Qatari girls. Therefore, multivariable regression model estimates of student attitudes toward going to school for Qatari male, non-Qatari male, Qatari female, and non-Qatari female students are considered to further understand the patterns between student attitudes toward going to school, learning, and future aspirations by student sub-groups. Table 4 presents model estimates of student attitudes toward going to school for Qatari boys, non-Qatari boys, Qatari girls, and non-Qatari girls. When disaggregated by student subgroups, model estimates find that student mindset towards learning and future aspirations in addition to overall teaching and classroom environment influence students differently. Model estimates show that student demonstration of learning behavior in and outside the classroom is the only student mindset factor that has a significant positive relationship with attitudes toward going to school consistently across all students, with this factor having the greatest influence on Qatari girls' attitudes toward going to school and the least on Qatari boys. This finding is consistent with wider literature that suggests that students who demonstrate learning behavior (e.g., paying attention in class, asking and answering questions in class, making an effort to learn in and outside the classroom, etc.) tend to have higher academic achievement and engagement with school (Crede, Roch, \& Kieszczynka, 2010; De-Hass, Willems, \& Holbein, 2005; Robbins et al., 2004).

Table 4. Regression model estimates for student attitudes toward going to school

\begin{tabular}{lcccc}
\hline Dependent Variable: Student attitudes toward going to school & & & \\
\hline & Qatari Boy & Non-Qatari Boy & Qatari Girl & Non-Qatari Girl \\
\hline Articulate importance of education & $0.712^{* * *}$ & 0.306 & $0.417^{* *}$ & 0.0751 \\
& $(0.226)$ & $(0.398)$ & $(0.174)$ & $(0.223)$ \\
Display of learning Behavior & $0.548^{* * *}$ & $0.651^{* * *}$ & $0.664^{* * *}$ & $0.631^{* * *}$ \\
& $(0.118)$ & $(0.186)$ & $(0.110)$ & $(0.126)$ \\
Aspiration to attend university & $0.404^{*}$ & $0.994^{*}$ & $0.499^{*}$ & 0.107 \\
& $(0.243)$ & $(0.590)$ & $(0.288)$ & $(0.384)$ \\
Learning is useful & $0.255^{* *}$ & 0.0232 & $0.222^{* * *}$ & $0.423^{* * *}$ \\
& $(0.0987)$ & $(0.139)$ & $(0.0704)$ & $(0.104)$ \\
\hline Teaching \& Classroom Environment & & & & \\
\hline Encouraging relationships fostered & 1.427 & 2.771 & 0.876 & -0.00395 \\
& $(2.622)$ & $(4.735)$ & $(1.516)$ & $(1.293)$ \\
Engaging learning environment created & 2.610 & $-12.42^{* * *}$ & $3.312^{* *}$ & 0.395 \\
& $(2.780)$ & $(4.505)$ & $(1.517)$ & $(1.502)$ \\
Learning is internalized & $26.20^{* * *}$ & -0.433 & 1.047 & 1.816 \\
Positive culture and learning environment & $(10.02)$ & $(12.00)$ & $(1.673)$ & $(1.344)$ \\
is fostered & $6.895^{* *}$ & $7.626^{* *}$ & -0.753 & 0.362 \\
Rigorous expectations held & $(2.966)$ & $(3.468)$ & $(0.734)$ & $(0.603)$ \\
Student input valued & -1.266 & 1.587 & -0.627 & -0.578 \\
Checking for understanding ${ }^{1}$ & $(3.090)$ & $(3.213)$ & $(1.507)$ & $(2.148)$ \\
& $-34.61 * * *$ & 5.600 & -1.279 & -0.189 \\
& $(10.57)$ & $(11.68)$ & $(2.274)$ & $(1.588)$ \\
& & & -2.438 & -1.922 \\
\hline
\end{tabular}




\begin{tabular}{lcccc}
\hline Constant & & & $(1.620)$ & $(1.535)$ \\
& $-3.549 * *$ & -1.436 & -0.882 & -0.480 \\
& $(1.554)$ & $(2.083)$ & $(0.702)$ & $(0.999)$ \\
Observations & 173 & 126 & 331 & 297 \\
R-squared & 0.330 & 0.376 & 0.263 & 0.283 \\
Robust standard errors in parentheses; & & & & \\
\hline$* * * \mathrm{p}<0.01, * * \mathrm{p}<0.05, * \mathrm{p}<0.1$. & & &
\end{tabular}

Whereas there appears to be a positive, significant relationship between articulation of the importance and/or value of education and attitudes toward going to school for Qatari male and Qatari female students, this relationship does appear to be significant for non-Qatari male and non-Qatari female students. Likewise, expression of learning in the classroom to be useful seems to be positively correlated with higher attitudes toward going to school for Qatari male and Qatari female students. However, unlike that for articulation of importance of education, expression of learning in the classroom as useful seem to be positively associated with higher attitudes toward going to school for non-Qatari female students as well but not for non-Qatari male students. Therefore, model estimates show that Qatari students' attitudes toward going to school are significantly and positively influenced by their ability to articulate the importance and/or value of education in addition to their belief that learning in the classroom is important compared to the non-Qatari students. This further indicates that Qatari students may be more value-driven when it comes to attitudes toward going to school compared to non-Qatari students. This phenomenon can be explained by examining patterns of qualitative responses of students where they articulated the reason for why they believe that education is valuable and/or important. Qualitative analysis of open-ended student responses revealed that one of the most common reasons that Qatari students provided were the ideas that education is important for development of the country and for the future generation. It can therefore be deduced from student responses and model estimates that Qatari students, who express a desire to contribute to society in the future, or at least understand the importance of country's future development, are also more likely to be engaged with school and the learning process.

Unlike the results from the aggregate model (Table 3), disaggregated model estimates evince that aspiration to attend university is weakly associated with attitudes toward going to school. In fact, this relationship is only statistically significant at $\mathrm{p}<0.1$ for Qatari boys, non-Qatari boys, and Qatari girls and statistically insignificant for non-Qatari girls. This result is consistent with earlier bivariate analysis, which indicated that difference in attitudes toward going to school among students with "low" and "high" orientation toward desiring to enroll in university is small. Hence, resulting analysis suggests that future aspirations for higher education is not a strong influencer for attitudes toward going to school compared to other factors at least for the surveyed grade 7 and 8 students in Qatar's independent schools. Although aspiration to enroll in university at an aggregate level seems to be a significant influencer for student engagement with school, the finding that this variable is not as significant when disaggregated by student sub-groups for Qatar's independent school context. This is inconsistent with other studies in US and Australian contexts that have found student aspiration to enroll in tertiary study to be a significant influencer for student engagement with school, and future aspirations have served to be one of the motivating factors for students to engage in school (Fullarton, 2002; Hill \& Wang, 2014). Nevertheless, provided that this variable is still significant at the aggregate level, findings from this study do not seem to contradict wider literature that finds a positive relationship between student aspirations to attend university, academic achievement, and student school engagement. In fact, a potential reason for why this variable is not highly significant may be that students at the preparatory (middle school) stage are too young to be heavily influenced by desire to enroll in university when it comes to school engagement. Another potential reason is that that students take enrolment in university as a given reality for the future to the point that this no longer becomes a significant influencer, i.e., is irrelevant, for student attitudes toward going to school.

When teaching and classroom environment is considered according to gender and nationality, regression model estimates indicate that teaching and classroom environment affect students differently. Model estimates from the aggregate model (Table 3) revealed that classroom and teaching environment on average does not have a significant influence on student attitudes toward going to school. However, model estimates from Table 4 
suggest that fostering of positive culture in the classroom, creation of an engaging learning environment, teacher ensuring that learning is internalized, and teacher valuing student input do influence some sub-groups of grade 7 and 8 students in Qatar's independent schools. Model estimates evince that, on average, fostering positive culture and learning environment is positively associated with higher attitudes toward going to schools in boys but not for girls, regardless of nationality. This supports other studies that show that creating supportive, caring classroom and school environments likely increase students' likelihood to be motivated and engaged in school and further suggests that this phenomenon may be more true for boys than girls in early adolescence (Klen \& Connell, 2007; Ryan \& Patrick, 2001; Uline \& Tschaannen-Moran, 2008).

Teacher ensuring that learning is fully internalized in students corresponds positively with higher attitudes toward going to school for Qatari boys, further indicating that boys may be more influenced by the overall teaching and classroom environment than girls. Creation of an engaging learning environment appears to correspond positively with higher attitudes toward going to school for Qatari girls but negatively for non-Qatari boys. This is surprising given other literature that suggests that fostering an engaging and active learning environment is positively correlated with student engagement and achievement (Ferguson, 2012; Akey, 2006). What is also unexpected is that teacher valuing student input is negatively associated with attitudes toward going to school for Qatari boys. It may be that teachers who foster an engaging learning environment and/or value student input require greater, more active participation from students, which may adversely influence attitudes toward going to school among students who are either already disengaged or do not desire to put effort during class. If this is the case for a significant number of male students, this may possibly explain the negative association with attitudes toward going to school though further research would be necessary to test for this hypothesis. Nonetheless, model estimates indicate that teaching and classroom environment has a more significant influence on student attitudes toward going to school for boys compared to girls, suggesting that boys are more affected by their learning environment than the girls when it comes to engagement. Studies in the UAE has shown that boys' schools were inferior in terms of teaching quality, which is likely to be the case in Qatar as well given the overall concerns about quality of teaching in Qatar's independent schools, particularly that in boys' schools (Ridge, 2014; Zellman et al., 2009). Hence, a potential explanation for the significance of the teaching and classroom environment for boys may be that even slightly higher teacher quality, which would presumably mean better teaching and classroom environments, makes a greater difference in students' engagement with school for boys than girls given the relative poor average quality of teaching and classroom environment.

Wider literature that suggests that boys are less engaged than girls in school and more likely to drop out in later years (Archambault, Jansoz, Fallu, \& Pagani, 2009; Makkawi, 2011; Yazzie-Mintz, 2007). Given this, this paper's findings on gender and nationality differences in the influencers for student attitudes toward and engagement with school are relevant to contexts outside of Qatar, as they can provide further insights into the relationships between student attitudes, motivation, behavior, and engagement with school. For example, finding from Qatar's experience that boys appear to be more influenced by the teaching and classroom environment compared to the girls may be applicable in other Arab Gulf countries, which experience similar challenges around underachievement of boys, in addition to countries that also see underachievement of boys in school (Fortin, Oreopoulos, \& Phipps, 2015). Likewise, the finding that the nationals' (i.e., Qatari students') attitudes toward school appear to be more influenced compared to their counterparts by their belief in the importance of education, particularly as it relates to country's future development. This potentially suggests to other contexts that also experience underachievement or lack of engagement that facilitating experiences for students make the connection between importance of education and national development may have a positive influence in improving students' school engagement.

\section{Conclusion and Implications}

This paper investigated the patterns underlying student attitudes toward going to school in relation to their mindset and behavior toward towards learning, school, and future aspirations. Consistent with wider literature (Furrer \& Skinner, 2003; Goetz et al., 2006; Mensah et al., 2013), findings reveal that student articulation of the importance of education, expression that learning in the classroom is useful, demonstration of learning behavior, and future aspirations to enroll in university to be positively associated with attitudes toward going to school. Nonetheless, contrary to wider literature (Kane et al., 2014; Klem \& Connell, n.d.), findings suggest that the relationship between the overall classroom and teaching environment and student attitudes toward going to school is not highly significant. This posits that at least among grade 7 and 8 students in Qatar's government schools, students are more affected by their own mindset toward learning, education, and aspiration for higher education than the overall classroom and teaching environment when it comes to their attitudes toward going to 
school. Although the specific patterns and corresponding significant relationships may be limited to Qatar's independent preparatory school context, findings are also significant for wider literature, as it highlights how students' intrinsic motivational and attitudinal factors are significant influencers for students' attitudes toward going to school in early adolescence. In fact, insights from the paper suggest that having teachers and educational curricula address the more intrinsic and attitudinal factors more explicitly may help engage students in school in early secondary years. This is particularly relevant, as literature finds that a large number of school dropouts occur during the transition between early secondary to upper secondary years (Wigfield \& Eccles, 2002; Skinner, Furrer, Marchand, \& Kinderman, 2008).

Additionally, gender and nationality differences were identified. On average, male and Qatari students have less positive attitudes toward going to school compared to their female or non-Qatari counterparts. It is unclear whether Qatari boys have significantly lower attitudes toward going to school compared to their counterparts based on model estimates. However, it appears that Qatari boys seem to have the lowest and the non-Qatari girls to have the highest mindsets regarding learning, school, and aspirations to pursue higher education. This finding is consistent with other studies in the Arabian Gulf and wider Middle East that found that males underachieve and participate in education less than females, as evidenced by overall performance of boys compared to girls in both international and national assessments and enrolment in higher education (Makkawi, 2011; Mullie et al., 2012). Despite this gender gap, there has not been policies or programs developed to target the widening gap between the boys and girls (Ridge, 2014). Furthermore, review of literature has demonstrated that this gender gap is not unique to the Arab Gulf context, as other studies, such as those in the US and Canada, have suggested that boys' school engagement is lower than that of girls (Fortin, Oreopoulos, \& Phipps, 2015; Yazzie-Mintz, 2007; Shapka, Domene, \& Keating, 2012). Hence, findings from this paper draw further attention to the need to engage with and motivate male students in the education process from an early age in order not to widen the gender gap in later years.

As discussed previously, analysis suggests that student articulation of the importance and/or value of education, in addition to belief that learning in the classroom is useful, influences students' attitudes toward going to school for Qatari students compared to non-Qatari students. Furthermore, in examining the patterns and relationships between student mindset and attitudes toward school, learning, and future aspirations by gender and nationality, findings indicate that Qatari boys, who on average have lowest attitudes and mindsets, are influenced by more value-based mindsets regarding to importance and/or usefulness of education and learning. In fact, one of the primary reasons that was most commonly articulated by Qatari students who had higher attitudes toward going to school on why education is important was that it is important for national development. Other common responses among students who had high attitudes toward going to school were that education is important for future career and/or life and that it is important to be able to achieve one's goals.

Patterns of Qatari students' responses to why education is important are consistent with findings from the Qatar employability study, which found that Qataris, especially Qatari males, were largely motivated by their desire to help and/or contribute to the country and money in seeking employment (Benchiba-Savenius et al., 2016). Findings from the employability study, in fact, affirm the paper's findings on student motivators for education, which further indicates that Qataris may be largely be motivated by their responsibility to their family, society, and country and that these responsibilities will serve as important motivators for Qataris' current and future education and career choices. This suggests that focusing on the value and importance of education and connecting this to ideas such as students' individual future life success, achievement of desires and/or goals, and contribution to nation's development may be beneficial in motivating and enhancing Qatari students' engagement with school. Moreover, provided that boys on average seem to be more significantly influenced by the teaching and classroom environment than girls, actively incorporating and speaking about the value of education and connecting importance of education for students' future and further development of nation in the classroom may be effective in improving Qatari boys' engagement and attitudes toward school.

If policy makers and practitioners wish to improve student' engagement with school and learning outcomes with the goal of building a knowledge-based economy, findings from this paper suggest that it then may be worth considering placing greater emphasis on values, relevance, and importance of learning in the classroom and school through curriculum, teaching practice, and extracurricular or co-curricular activities. One of the ways to do this is through a more relevant $21^{\text {st }}$ century curriculum and civic education that help students make the connections between learning in the classroom, relevance to current and future life, and education's contribution to the country's development. In fact, studies have demonstrated that fostering civic engagement and $21^{\text {st }}$ century learning in communities have been affected in improving student performance, both in terms of academic and non-academic achievement such as attendance and behavior (Rochford \& Hock, 2012; Dodd, 2011). Although 
these studies were conducted in the US context, findings may have applicability to Qatar and the wider Arab Gulf context where values and desire to contribute to society seem to be significant drivers and motivators for education and career choices.

In conclusion, this paper's findings are meaningful first for researchers who are interested in Qatar's education landscape, as it provides a quantitative examination into student mindsets and motivation in Qatar's independent school system, an area that has not been investigated often. Moreover, as illustrated above, insights from the study are also relevant for policy makers and education practitioners in Qatar, as policy implications can be inferred and developed from the findings, particularly as they relate to Qatari males, subgroup of high interest of recent years from a policy perspective. The scope of this paper is limited to the Qatari context. Nonetheless, insights from this paper are highly relevant to the wider Arab Gulf context, as Arab Gulf countries not only have walked similar education development trajectories but also face similar challenges of student motivation and engagement, particularly amongst its national and male population (Barber, Mourshed, \& Whelan, 2007; De Boer $\&$ Turner, 2007; Shediac, 2010). Not only so, the paper adds to wider literature on student mindsets, motivation, and attitudes toward learning, school, and future aspirations by empirically considering student perspectives. Findings contribute to wider literature by suggesting that students' intrinsic motivational and attitudinal attitudes may be more significant than the teaching and classroom environment in which the student learns, although the classroom and school environment cannot be ignored. Furthermore, this paper supports other studies that have found a gender gap in student engagement, where boys seem to have lower levels of engagement compared to girls, by showing how this phenomenon is not limited to Western contexts, where the majority of these studies have been conducted.

Despite the contribution of this paper to wider literature on education and the learning environment in Qatar and to an extent the Arab Gulf context, limitations to the scope of analysis presented in this paper exist. Firstly, the scope of data analyzed in this paper is limited not only to a single data collection event, the quality of which is inevitably dependent on conditions of the context of the given time, but also to grade 7 and 8 students in Qatar's independent schools. It is therefore important to note that findings from this paper may be limited to and relevant for this group of students and not presume that results would be similar for other groups of students, i.e., those in private schools or in different levels of education. Another limitation is that analysis was based on self-reported student questionnaires. Although there is value in capturing student voice and understanding student perspectives, particularly as the scope of the study is focused on student mindsets and attitudes, student responses are likely to be positively biased. Limitations of the paper nonetheless provide direction for future research to understand the drivers and motivators that influence students' attitude and engagement with school and learning. A more comprehensive investigation of student mindsets and attitudes would require consideration of student perspectives across more balanced numbers of male and female students in multiple grade levels in the independent preparatory schools. Furthermore, consideration of student perspectives of those attending private schools may be able to provide comparison between attitudes toward learning and future aspirations between those who attend private school and public schools in Qatar.

\section{Acknowledgments}

I would like to thank Teach For Qatar for granting permission for use of student survey data for research purposes. Moreover, I would like to acknowledge and thank all school administrators, teachers, and students who facilitated and partook in the student surveys.

\section{References}

Akey, T. (2006). School context, student attitudes and behavior, and academic achievement: An exploratory analysis MDRC. Retrieved from http://mdrc.org/sites/default/files/full_519.pdf.

Al Thani, M. (2012). The Arab Spring \& the Gulf States: Time to Embrace Change. London: Profile Books.

Appleton, J., Christenson, S., \& Furlong, M. (2008). Student engagement with school: Critical conceptual and methodological issues of the construct. Psychology in the Schools, 45(5). http://dx.doi.org/10.1002/pits.20303

Archambault, I., Janosz, M., Fallu, J., \& Pagani, L. (2009). Student engagement and its relationship with early school dropout. Journal of Adolescence, 32, 651-670. http://dx.doi.org/10.1016/j.adolescence.2008.06.007

Ashcraft, N. (2007). UAE pre-service teachers' motivations for entering the world of TESOL. In L. Stephenson, \& P. Davidson (Eds.), Teacher education and continuing professional development: Insights from the Arabian Gulf (pp. 27-42). Arabia: TESOL. 
Barber, M., Mourshed, M., \& Whelan, F. (2007). Improving education in the Gulf (McKinsey Quarterly, Rep.). London: McKinsey \& Company.

Benchiba-Savenius, N., Mogielnicki, R., Owens, S., \& Scott-Jackson, W. (2016). Qatar employment report. Oxford strategic consulting. Retrieved from http://www.oxfordstrategicconsulting.com/wp-content/uploads/2016/02/OxfordStrategicConsulting_QatarE mployment_Jan2016.pdf

Bernstein, D. A., Penner, L. A., Clarke-Stewart, A., \& Roy, E. J. (2006). Psychology (7th ed.). Boston: Houghton Mifflin Company.

Candeias, A., Rebelo, N., \& Oliviera, M. (2013). Students' attitudes toward learning and school-study of exploratory models about the effects of socio-demographics and personal attributes. Retrieved from http://www.projectored.uevora.pt/ documentos/LICE.pdf

Crede, M., Roch, S., \& Kieszczynk, U. (2010). Attendance in college: A meta-analytical review of the relationship of class attendance with grades and student characteristics. Review of Educational Research, 80(2), 272-295. http://dx.doi.org/10.3102/0034654310362998

De Boer, K., \& Turner, J. M. (2007). Beyond oil: Reappraising the Gulf States (McKinsey Quarterly, Rep.). London: McKinsey \& Company.

De-Hass, A., Willems, P., \& Holbein, M. (2005). Examining the relationship between parental involvement and student motivation. Educational Psychology Review, 17(2), 99-123. http://dx.doi.org/10.1007/s10648-005-3949-7

Dodd, A., \& Bowen, L. (2011). $21^{\text {st }}$ century community learning centers-Improving the academic performance of at-risk students: A Bronx tale. Journal of Health \& Human Services, 34(1).

Eccles, J. S., Wigfield, A., \& Schiefele, U. (1998). Motivation to succeed. In W. Damon (Series Ed.), \& N. Eisenberg (Vol. Ed.), Handbook of child psychology: Social and personality development (Vol. 4, pp. 1017-1095). New York: Wiley.

Engin, M., \& McKeown, K. (2012). Cultural influences on motivational issues in students and their goals for studying at university. Learning and Teaching in Higher Education: Gulf Perspectives, 9(1).

Ferguson, R. F. (2012). Can Student Surveys Measure Teaching Quality? Phi Delta Kappan, 94(3), 24-28. http://dx.doi.org/10.1177/003172171209400306

Fortin, N., Oreopoulus, P., \& Phipps, S. (2015). Leaving boys behind: Gender disparities in high academic achievement. The Journal of Human Resources, 50(3). http://dx.doi.org/10.3368/jhr.50.3.549

Fullarton, S. (2002). Student engagement with school: Individual and school-level influences. LSAY Research Reports. Retrieved from http://research.acer.edu.au/lsay_research/31

Furrer, C., \& Skinner, E. (2003). Sense of relatedness as a factor in children's academic engagement and $\begin{array}{lllll}\text { performance. Journal of Education } & \text { Psychology, }\end{array}$ http://dx.doi.org/10.1037/0022-0663.95.1.148

Goetz, T., Hall, N. C., Frenzel, A. C., \& Pekrun, R. (2006). A hierarchical conceptualization of enjoyment in students. Learning and Instruction, 16(4), 323-338. http://dx.doi.org/10.1016/j.learninstruc.2006.07.004

Hertog, S. (2010). The sociology of Gulf rentier systems: Societies of intermediaries. Comparative Studies in Society and History, 52(2), 1-37. http://dx.doi.org/10.1017/S0010417510000058

Hill, N., \& Wang, M. (2014). From middle school to college: Developing aspirations, promoting engagement, and indirect pathways from parenting to post high school enrollment. Developmental Psychology, 51(2), 224-235. http://dx.doi.org/10.1037/a0038367

Jimerson, S. R., Campos, E., \& Greif, J. L. (2003). Toward an Understanding of Definitions and Measures of School Engagement and Related Terms. The California School Psychologist, 8(1), 7-27. http://dx.doi.org/10.1007/BF03340893

Johnson, M., Crosnoe, R., \& Elder, G. (2001). Students' attachment and academic engagement: The role of race and ethnicity. Sociology of Education, 74(4), 318-340. http://dx.doi.org/10.2307/2673138

Kabbani, N., \& Kothari, E. (2005). Youth employment in the MENA region: A situational assessment. Washington, DC: World Bank. 
Kane, T., Kerr, K., \& Pianta, R. (2014). Designing teacher evaluation systems: New guidance from the measures of effective teaching project. San Francisco, CA: Jossey-Bass.

Klem, A., \& Connell, J. (2004). Relationships matter: Linking teacher support to student engagement and $\begin{array}{lllll}\text { achievement. Journal of } & \text { 262-273. }\end{array}$ http://dx.doi.org/10.1111/j.1746-1561.2004.tb08283.x

Linnehan, F. (2001). Examining racial and family educational background differences in high school student beliefs and attitudes toward academic performance. Social Psychology of Education, 5(1), 31-48. http://dx.doi.org/10.1023/A:1012723816735

Lumby, J. (2011). Enjoyment and learning: Policy and secondary school learners' experience in England. British Educational Research Journal, 37(2), 247-264. http://dx.doi.org/10.1080/01411920903540680

Maio, G. R., \& Haddock, G. (2009). The psychology of attitudes and attitude change. London: SAGE.

Makkawi, I. (2011). Success against the odds: Palestinian female students outperform their male counterparts in academic achievement. Arab Studies Quarterly, 33(1), 44-61.

Mensah, J., Okyere, M., \& Kuranchie, A. (2013). Student attitude towards mathematics and performance. Does teacher attitude matter. Journal of Education and Practice, 4(3), 132-139.

Mullis, L. V., Martin, M., \& Foy, P. (2012). Trends in International Mathematics and Science Study (TIMSS) 2011 International Results in mathematics. Boston: International Association for the Evaluation of Educational Achievement.

OECD (Organization for Economic Cooperation and Development). (2013). PISA 2012 Results: What students know and can do (Report). Paris: OECD.

OECD. (2014). PISA 2012 results in focus: What 15 year olds know and what they can do with what they know (Publication). Paris: OECD.

Patrick, H., Ryan, A. M., \& Kaplan, A. (2007). Early adolescents' perceptions of the classroom social environment, motivational beliefs, and engagement. Journal of Educational Psychology, 99(1), 83-98. http://dx.doi.org/10.1037/0022-0663.99.1.83

Qatar General Secretariat for Development Planning. (2011). Qatar national development strategy 2011-2016: Towards Qatar national vision 2030. Retrieved from http://www.gsdp.gov.qa/gsdp_vision/docs/NDS_EN.pdf

Ridge, N. (2012). In the shadow of global discourses: Gender, education and modernity in the Arabian Peninsula. In G. Steiner-Khamsi, \& F. Waldow (Eds.), World Yearbook of Education 2012: Policy borrowing and education (pp. 291-308). New York: Routledge.

Ridge, N. (2014). Education and the Reverse Gender Divide in the Gulf States: Embracing the Global, Ignoring the Local. New York: Teachers College Press.

Robbins, S. B., Lauver, K., Le, H., Davis, D., Langley, R., \& Carlstrom, A. (2004). Do psychosocial and study skill factors predict college outcomes? A meta-analysis. Psychological Bulletin, 130, 261-288. http://dx.doi.org/10.1037/0033-2909.130.2.261

Rochford, R. A., \& Hock, S. (2012). A letter-writing campaign: Linking academic achievement and civic engagement. Journal of community engagement and scholarship, 3(2).

Rudd, P., Reed, F., \& Smith, P. (2008). The effects of the school environment on young people's attitudes toward education and learning. National Foundation for Educational Research. Retrieved from https://www.nfer.ac.uk/nfer/publications/BSY01/BSY01.pdf

Ryan, A. M., \& Patrick, H. (2001). The classroom social environment and changes in adolescents' motivation and engagement during middle school. Am Educ Res Journal, 38(2), 437-460. http://dx.doi.org/10.3102/00028312038002437

SESRI. (2013). Qatar Education Study 2012: Students' Motivation and Parental Participation Report (Rep.). Doha: Qatar University.

Shapka, J., Domene, J., \& Keating, D. (2012). Trajectories of educational aspirations through high school and beyond: A gendered phenomenon? Canadian Journal of Education, 35(1), 239-258. 
Shediac, R. (2010). Meeting the Employment Challenge in the GCC: The Need for a Holistic Strategy (Booz \& Company Ideation Center Insight, Rep.). Booz \& Company.

Shernoff, D. J., Csikszentmihalyi, M., Shneider, B., \& Shernoff, E. S. (2003). Student engagement in high school classrooms from the perspective of flow theory. School Psychology Quarterly, 18(2), 158-176. http://dx.doi.org/10.1521/scpq.18.2.158.21860

Shochat, S. (2008). The Gulf Cooperation Council Economies: Diversification and Reform. Kuwait: LSE.

Sinclair, M. F., Christenson, S. L., Lehr, C. A., \& Anderson, A. R. (2003). Facilitating Student Engagement: Lessons Learned from Check \& Connect Longitudinal Studies. The California School Psychologist, 8(1), 29-41. http://dx.doi.org/10.1007/BF03340894

Skinner, E., Furrer, C., Marchand, G., \& Kindermann, T. (2008). Engagement and disaffection in the classroom: Part of a larger motivational dynamic? Journal of Educational Psychology, 100(4), 765-781. http://dx.doi.org/10.1037/a0012840

Stiglitz, J. (1999). Public policy of a knowledge economy. London: Department for Trade and Industry and the Center for Economic Policy Research.

Stipek, D. J. (2002). Motivation to learn: From theory to practice (4th ed.). Needham Heights, MA: Allyn \& Bacon.

Tyler, K. M., \& Boelter, C. M. (2008). Linking black middle school students' perceptions of teachers' expectations to academic engagement and efficacy. Negro Educational Review, 59(1/2), 27-44.

Uline, C., \& Tschannen, M. (2008). The walls speak: The interplay of quality facilities, school climate, and student $\begin{array}{llll}\text { achievement. Journal of Educational Administration, } & \text { 46(1), }\end{array}$ http://dx.doi.org/10.1108/09578230810849817

Van Houtte, M. V. (2004). Why boys achieve less at school than girls: The difference between boys' and girls' academic culture. Educational Studies, 30(2), 159-173. http://dx.doi.org/10.1080/0305569032000159804

Wigfield, A., \& Eccles, J. S. (2002). Development of achievement motivation. San Diego: Academic Press.

Yazzie-Mintz, E. (2007). Voices of student engagement: A report on the 2006 high school survey of student engagement. Bloomington: Center for Evaluation \& Education Policy, Indiana University. Retrieved from http://files.eric.ed.gov/fulltext/ED495758.pdf

Zellman, G., Ryan, G., Karam, R., Constant, L., Salem, H., Gonzalez, G., ... Al-Obaidli, K. (2009). Implementation of the K-12 Education Reform in Qatar. Santa Monica, CA: RAND Corporation.

\section{Notes}

Note 1. Independent preparatory schools in Qatar are government (public) schools that serve grade 7, 8, and 9 students. Government schools in Qatar are separated by gender.

Note 2. The 7 categories of teaching and learning environment measured by the Student Tripod Survey are the following. 1) Encouraging and supporting relationships fostered ["Care"]; 2) Engaging learning environment established ["Captivate"]; 3) Learning is fully internalized ["Clarify"]; 4) Positive culture and learning environment is created ["Control"]; 5) Rigorous expectations are held ["Challenge"]; 6) Student input and ideas are valued ["Confer"]; and 7) Understanding is checked for and ensured ["Consolidate"].

\section{Copyrights}

Copyright for this article is retained by the author(s), with first publication rights granted to the journal.

This is an open-access article distributed under the terms and conditions of the Creative Commons Attribution license (http://creativecommons.org/licenses/by/3.0/). 